TABLE III.

Solubility of Acetanilide, Phenachine, Caffeine and Salol in Organic SOLVENTS.

\begin{tabular}{|c|c|c|c|c|c|c|}
\hline \multirow{3}{*}{$\begin{array}{l}\text { Solvent. } \\
{ }^{1} \text { Water }\end{array}$} & \multirow{2}{*}{\multicolumn{2}{|c|}{$\begin{array}{l}\text { Sp. gr. } \\
\text { of solvent. } t^{\prime \prime}\end{array}$}} & \multicolumn{4}{|c|}{ Grams per roo grams saturated solution } \\
\hline & & & Acetanilide. & henacetine. & Caffeine. & \\
\hline & 0.997 & 25 & o. & O.II & 2.1 & \\
\hline${ }^{1}$ Ether & 0.716 & $\because$ & 7.7 & .56 & 0.27 & \\
\hline${ }^{1} \mathrm{Ch}$ loroform & $1.47^{6}$ & “ & & 4.76 & II.O & \\
\hline Acetone & 0.827 & $30-3 I$ & 3 I. $5(0.902)$ & 10.68 & 2.18 & 90.99 \\
\hline Benzene & 0.872 & $\because$ & $2.46(0.875)$ & $0.65(0.873)$ & $2(0.875)$ & $88.57($ I.148) \\
\hline lehyde & 1.055 & “ & $.068)$ & $8.44(1.063)$ & I I. & ? \\
\hline acetate & 0.860 & “ & $10.46(0.882)$ & $2.42(0.865)$ & $0.72(0.862)$ & $85.29(1.136)$ \\
\hline Anili & I.02 & “ & $19.38(1.034)$ & $9.46(\mathrm{~T} .025)$ & $22.89(1.080)$ & very soluble \\
\hline lcohol & $0.8 I_{4}$ & 25 & 14.00 & 3.51 & $0.49(0.810)$ & $20.44(0.869)$ \\
\hline Acetic acid ${ }^{2}$ & 1.055 & $2 \mathrm{I} .5$ & 33.21 & $13.65(1.064)$ & 2.44 & $63.24($ I.I 43$)$ \\
\hline Xylene & 0.847 & $3^{2.5}$ & I.65 $(0.847)$ & I. $25(0.847)$ & I. I [ $(0)$ & $87.14 \div$ \\
\hline Toluene & 0.862 & 25.0 & $0.50(0.862)$ & $0.30(0.863)$ & $0.57(0.861)$ & $8_{3.62}(1.12 S)$ \\
\hline
\end{tabular}

Figures in parentheses are the specific gravities of the saturated solutions.

Fairly good results have been obtained by the author in separating mixtures of different amounts of salol, caffeine, and acetanilide by digesting first in toluene for the removal of salol and then in amyl alcohol for the removal of the acetanilide.

As is shown by the table, none of the four compounds are completely insoluble in any of the solvents, and consequently it cannot be expected that a very sharp separation can be made. This is especially true for mixtures containing relatively small amounts of either of the substances. It is also to be mentioned that the influence of the presence of one substance upen the solubility of the others in the mixture has not been investigated and therefore conclusions based upon the solubility of single stubstances in a given solvent may be considerably in error when applied to mixtures of two or more substances acted upon by the same solvent.

The author regrets that circumstances have prevented the extension of these determinations to a larger number of solvents and the application of the results to a more accurate method of separating and determining the constituents of headache powders.

[Contribution from the Drug Laboratory, Bureau of chemistry, PubLISHED by PERMISSION OF THE SECRETARY OF AgRICULTURE].

\title{
A RAPID METHOD FOR THE QUANTITATIVE DETERMINATION OF ACETANILIDE IN HEADACHE POWDERS.
}

By ATHERTON SEIDELl.

Received May 2, 1902.

While continuing the investigations described in the previous paper a suggestion was obtained which has led to the following method for deter-

${ }^{1}$ Results from U. S. P., Sth Revision.

${ }^{2} 99.5 \%$ 
mining acetanilide in presence of many of the substances usually associated with it in the headache and nenralgia renedies found on the marlict.

In studying the distribution of phenol and of aniline between water ant sereral inmiscible solvents Vaube! ${ }^{1}$ and subsequently Riedel" titrated the phenol or aniline as the case night be with a standard solution of potassium bromate and found that very satisfactory determinations contil ixe made. The method is based upon the well lnown property of phenol ant of aniline to unite with bromine in a strongly acid arpucous solution to form the insoluble tri-bromide in each case. When the precipitation is complete the free bronine in solution is easily detected by the velion colur which it imparts to the liquid. A method based upon this same reaction is given for carbolic acici in the I89o $t$. S. Pharmacopoia, page 10 . Accorling to this nethod, however, the excess of added bromate solution (Foppeschaar's solution) is titrated back with standard sodium thiosulphate.

In view of the ready saponification of acetanilide in acid as well as alkaline solutions it was thought desirable to test the applicability of the above method to the determination of the aniline set free from acetanilice by saponification in strongly acid solutions. The preliminary experiments proved entirely satisfactory and it only remained to determine the limits of accuracy which could be attained and ascertain the inthence exerted by other substances in solution.

The standard potassium bromate solution may be conveniently prepared by adding bromine to a cold almost saturated aqueous solution of about one hundred grams of potassinm hyclroxicle, tuntil no more is taken up, cliluting somewhat with water and heating to expel the excess of bromine, filtering and bringing to a volmme of about two liters. The solution may be standardized with weighed anounts of cither pure aniline or acetanilide. In the latter case the acetanilide is first boiled several minutes in a moderately concentrated solution of hylrochloric acil and the hot solution titrated. The bromate solution is diluted so tinat each culbic centimeter corresponds to 0.01 gram of acetanilide; this being a convenient strength to use; although a more dilute standard solution may be used if desired.

Experiments made for the purpose of ascertaining the limits of strength of acid and time of heating necessary for complete saponification of acetanilide showed that the acid solution shotld contain not less than approximately I part of concentrated hydrochloric acid to 4 parts of water and the heating should be continued for at least an hour on the stean bath or the solution boiled energetically for five minutes. In these

${ }^{1}$ J. pr. Chem., (2) 67, 476, (1903).

${ }^{2}$ Z. physik. Chem., 56, 243, (1906). 
experiments half gram samples of acetanilide and approximately $60 \mathrm{cc}$. of the acid solution were used, and the mixtures heated in $200 \mathrm{cc}$. Erlenmeyer flasks.

In regard to the accuracy which may be attained it was found that with half gram samples of acetanilide, the amounts recovered as calculated from the $\mathrm{cc}$. of standard bromate used agree in practically all cases to within one per cent. of the weight of acetanilicle taken.

The next point investigated was the effect upon the reaction of other substances in solution. Among the first of these considered was caffeine It was found that with half gram samples of acetanilide amounts of caffeine varying between one-half and two grams did not interfere at all with the accuracy of the titration. It is very probable that the presence of caffeine in even larger relative amounts would not seriously affect the accuracy of the determinations although it was noticed that with the larger amounts of caffeine there is some tendency for the yellow color of the free bromine in the solution at the end of the titration to fade on standing.

As is of course to be expected, sodium bicarbonate and other unoxidizable inorganic salts which may possibly be used in headache powders do not interfere with the accurate titration of the acetanilide.

With sugar, which is a frequent constituent of this class of medicines it is found that heating to the temperature of the steam bath or boiling with hydrochloric acid of the concentration required for the saponification of the acetanilicle, causes the sugar to carbonize with a resulting darkening of the solution. The dark color prevents the detection of the end point of the reaction, but it is found that in such cases on cooling the solution and adding a little animal charcoal and filtering, the dark color may be satisfactorily removed and an accurate titration of the clear solution nade. A more satisfactory plan, however, is to remove the acetanilide from the sample by means of chloroform or some other solvent, and after evaporating the latter, determine the acetanilicle as above outlined. In sone cases, on the other hand, it may be desirable to dissolve out the sugar and other water soluble constituents with the least possible amount of cold water and then saponify the undissolved acetanilide with hydrochloric acid as described.

Experiments made with mixtures of salol and acetanilide showed that the accuracy of the determination is in no wise influenced by the presence of the salol.

The above named substances are the ones which are usually found in the ordinary headache and neuralgia. preparations which are sold by druggists and therefore the very simple and rapid method here described is applicable in the large majority of cases. In order to test the method, a number of heaclache powders containing various amounts of acetanilide 
mixed with sugar, sodium bicarbonate, caffeine, salol, etc, were preptred and the acetanilide cletermined by the titration as above lescribed, In all cases the amounts found agreed within a few tenths of a per cent, witin the amount which the sample was known to contain.

In acklition to acetanilicle, the only other stustances which have found extensive application in the relief of headaches are phenacetine and antipyrine but the use of these as compared with acetanilide has until recently been largely restricted on account of their higher price. The action of these substances upon the nerve centers is very similar to that of acetanilicle and for this reason it is not to be expected that they will gencrally be used together with acetanilicle in heaclache remedies, nevertheles: it was thought desirable to examine their influence upon the titration method described above. A few tests immerliately indicated the impossibility of titrating the saponified acetanilide solution with potassium bromate when even the smallest amount of either phenacetine or antipyrine is present in the original sample. In the case of phenacetine the first few drops of the bromate solution turns the licuid pink to purple color and this becomes darker, even to deep black with continued addition of the bromate solution. ${ }^{1}$ With the presence of antipyrine the end point of the titration is also obscured.

At the present time apparently the only satisfactory methods available for the quantitative determination of phenacetine and of antipyrine are the Zeisel "ethoxy and methoxy distillation methor for the former and liongault's "iodine titration method for the latter. A number of cleterminations made by the author with the Zeisel method indicated that the procedure can be carried out only by a shilled worker, and this fact together with the amount of time recuired for each determination will uncloubtedly. impair the usefulness of the method for ordinary practice in control laboratories. In regard to the method for antipyrine, it is evident that the determination can not be made upon samples containing caffeine or other substances which mite readily with free iodine. In view of these consiclerations it appeared especially desirable to modify the titration method for acetanilide proposed in the first part of this paper, in such a mamer that at least quantitative determinations of this substance in presence of phenacetine could be satisfactorily marle. With this idea in mind a very: large number of experiments have been made and so far only partial success has been attained. The cause of the difficulty lies in the presence of

'This observation suggests a simple test for detecting the presence of phenatctine in acetanilide. Dissolve the sample in moderately strong hydrochloric acid, boil and add a few drops of potassium bromate solution, a purple color indicates the presence of phenacetine.

"See Tingle's translation of Hans Meyers' little book upon the "Determination of Radicals in Carbon Compounds," p. $3^{8 .}$

3 J pharm. chim., (6) 7, 16I, 11, 97 . 
the ethoxy group in the phenacetine. The bromine acting upon this portion of the molecule converts the compound into an intensely colored quinone derivative which makes it impossible to observe the end point of the reaction. Among the plans for getting around this difficulty which have so far been tried without success may be mentioned, the attempts to remove or render the ethoxy group inactive either by oxidation or reduction methods; titration with the use of spotting plates or test papers upon removed portions of the solution; and the use of mild saponifying agents for liberating aniline from the acetanilide without acting upon the phenacetine.

It was found that although acetanilide alone, and with less success phenacetine, could be titrated directly (without previous saponification) in the cold, acidified, aqueous solution with standard potassium bromate, the reaction is slow since time must be allowed for the dissolving of the phenacetine or acetanilide during the titration, and in addition the presence of caffeine serionsly interferes with the determination of the end point.

The only process which has appeared to be worthy of further study is based upon the statements found in Meyer and Jacobsen, vol. 2, p. 455, that chloride of lime acting upon $p$-aminophenols produces quinone chloramicle and this product is very easily reduced back to the $p$-phenol by means of reducing agents. Quantitative experiments made with stannous chloride as the reducing agent showed that if an excess of the bromate solution be added to the acid saponified solution of a mixture of acetanilide and phenacetine, this excess could be titrated back with stannous chloride and the difference corresponds fairly closely to the amount required by the acetanilide alone in the mixture. Further work will be required however to demonstrate the practical applicability of this procedure; and in the mean time it is hoped that the method as described for acetanilicle alone will prove useful particularly to the chemists having charge of the enforcement of the new Pure Food and Drug Law.

\section{A STUDY OF THE INFLUENCE OF MAGNESIUM SULPHATE ON THE GROW'TH OF SEEDLINGS.}

By Gertrude s. BURLINGHAM.

Received March 29, I907.

\section{Introduction}

This investigation is an outgrowth of a more comprehensive problem in nutrition, the aim of which was to learn the effects of the different minerai nutrients upon the growth of a test plant, from these data to compound a perfect nutrient solution, and then to note the variations in structure and form which might be produced by modifying the composition of this nutrient solution. Abutilon abutilon was chosen as the test plant, 